\title{
Electrochemical Degradability of Al-20\% Mg and Al-22\% Si Alloys in an Acidic Environment in Relation with their Microstructure
}

\author{
Maamar Slimane and Farida Kellou-Kerkouche*
}

Laboratoire d'Electrochimie-Corrosion, Métallurgie et Chimie Minérale, Faculté de Chimie/USTHB BP32, El-Alia Bab-Ezzouar, Alger-Algérie

Received September 26, 2017; accepted January 5, 2018

\begin{abstract}
The electrochemical degradability of $\mathrm{Al}-20 \% \mathrm{Mg}$ and hypereutectic $\mathrm{Al}-22 \% \mathrm{Si}$ industrial alloys was evaluated in an aggressive acidic environment, namely $1 \mathrm{M}$ $\mathrm{H}_{2} \mathrm{SO}_{4}$, using potentiodynamic polarization, linear polarization resistance (LPR) and electrochemical impedance spectroscopy (EIS) techniques. The microstructure and constituting phases of the surface alloys were characterized by X-ray diffraction (XRD) and Scanning Electron Microscopy (SEM), coupled with Energy Dispersive X-ray Spectroscopy (EDX). It was found that the two alloys' corrosion behavior mainly depends on their crystalline phases. The presence of the active intermetallic $\beta-\mathrm{Al}_{3} \mathrm{Mg}_{2}$ phase in the $\mathrm{Al}$ alloy with high $\mathrm{Mg}$ content induced a preferential $\mathrm{Mg}$ dissolution, which caused a severe intergranular attack on this alloy by the corrosive solution. Meanwhile, the Al alloy containing high Si content, which presented the eutectic Al-Si phase, showed a uniform and weaker dissolution. It was also observed that a rise in temperature reduced the corrosion performance of the two studied alloys, as these corroded faster than pure aluminum.
\end{abstract}

Keywords: aluminum alloys, acid corrosion, potentiodynamic polarization, EIS, dealloying.

\section{Introduction}

In the recent decades, aluminum became the leader in the metallurgy of nonferrous metals. The development of applications for aluminum and its alloys is attributed to their several advantageous properties, particularly in the fields of packaging, transport, building, electrical and mechanical engineering, and so on [1]. Aluminum is very interesting, due to its thermal and electrical conductivities, ease of recycling, the wide variety of its alloys, and its low density, which is a property that is in great demand in the automotive industry, because it allows fuel consumption reduction [2].

\footnotetext{
*Corresponding author. E-mail address: fakellou62@gmail.com; fkellou@usthb.dz
} 
The most popular alloying elements of aluminum are silicon and magnesium (alloys of 5XXX and 4XXX series), which are added to improve some of the base metal's mechanical properties [3-9], but unfortunately reduce its corrosion resistance [10]. It is well known that the surface of aluminum and its alloys is covered with a native oxide film that naturally develops in air, under ordinary conditions [11]. However, this oxide does not offer them sufficient protection against corrosive solutions, since it is non-uniform, thin and non-coherent. In fact, this oxide is only stable in the $\mathrm{pH}$ range from 4.0 to 9 [12]. Several studies focused on the electrochemical behavior of $\mathrm{Al}$ and its alloys, in order to test their resistance to corrosion in different aggressive environments. It is noticed that most of these investigations were devoted to the low alloying Al materials [1319]. However, the corrosion behavior of Al-alloys, with high composition of $\mathrm{Mg}$ or high content of Si (hypereutectic Al-Si alloy), has not been thoroughly studied [20-21].

The Al-alloys with high silicon content are generally those containing over about $17 \mathrm{wt} \%$ of silicon. The hypereutectic Al-Si alloys are very interesting materials, due to their numerous properties, such as low coefficient of thermal expansion, low density and good corrosion resistance. However, with increased silicon content, the massive primary silicon and long needle-like eutectic silicon in hypereutectic Al-Si alloys split the matrix and reduce their performance [22]. The influence of the massive primary silicon on the corrosion resistance of Al$30 \% \mathrm{Si}$ in a $\mathrm{NaCl}$ solution was investigated [20]. The research showed that the refined primary silicon particles improved the corrosion resistance of this Al-Si alloy. Mazhar et al. [10] studied the Al-Si alloys eutectic phase effect on their electrochemical behavior in a $\mathrm{HCl}$ solution; they found that the hypoeutectic Al$11 \% \mathrm{Si}$ corroded faster than the hypereutectic $\mathrm{Al}-22 \% \mathrm{Si}$, due to its high eutectic content.

Aluminum alloys with a high content of $\mathrm{Mg}(\mathrm{Mg}>11$ wt. \%) are good candidates to replace some conventional alloys in the automotive industry, due to their low density and compressive strength. However, the $\beta-\mathrm{Al}_{3} \mathrm{Mg}_{2}$ brittle phase presence in the matrix reduces their ductility and, consequently, their mechanical properties [23]. In order to improve these properties, some studies have been devoted to a refined Al-Mg alloy structure, by addition of grain refiners, such as boron, titanium and zirconium [23-24] that provide a more homogeneous precipitates distribution.

The $\beta-\mathrm{Al}_{3} \mathrm{Mg}_{2}$ phase precipitation strongly influences the $\mathrm{Al}-\mathrm{Mg}$ alloys corrosion, in particular the 5xxx alloys which undergo an intergranular corrosion [25-26]. In order to get better insight on the intermetallic $\beta$-phase dissolution mechanism, Lyndon et al. [27] have synthesized the $\beta-\mathrm{Al}_{3} \mathrm{Mg}_{2}$ phase in the bulk form, to study its electrochemical behavior in a $\mathrm{NaCl}$ solution, at different $\mathrm{pHs}$. The main obtained result is that the dissolution rate of the intermetallic phase is $\mathrm{pH}$ dependent. On the other hand, Liu et al. [28] had some interest for the $\beta$ phase corrosion process in a $\mathrm{Na}_{2} \mathrm{SO}_{4}$ solution. These authors claimed that there was $\mathrm{Mg}$ dealloying, which is ascribed to the preferential $\mathrm{Mg}$ dissolution, and to the $\mathrm{Al}$ surface rearrangement into $\mathrm{Al}$ islands. 
Literature survey related to the corrosion of alloyed aluminum with high $\mathrm{Mg}$ or Si content reveals a great lack of fundamental data on their corrosion, particularly in acidic media. In fact, these alloys interact with atmospheric environments under some severe conditions, such as acid rain, which contains sulfuric acid as its main component.

In this context, we aimed to study, in one hand, the electrochemical behavior of $\mathrm{Al}-20 \% \mathrm{Mg}$ and hypereutectic $\mathrm{Al}-22 \% \mathrm{Si}$ alloys in a $1 \mathrm{M} \mathrm{H}_{2} \mathrm{SO}_{4}$ solution at various temperatures, and, on the other hand, to correlate the crystalline phases of the microstructure and the corrosion resistance of the two samples. In order to learn more about the two Al-alloys' corrosion mechanism, pure aluminum's electrochemical behavior was investigated in the acidic solution at $20{ }^{\circ} \mathrm{C}$. For this purpose, three electrochemical techniques were conducted to evaluate the electrochemical degradation degree of the studied materials in $1 \mathrm{M} \mathrm{H}_{2} \mathrm{SO}_{4}$.

\section{Experimental}

\section{Materials and characterization}

The aluminum materials employed in our study were supplied by the National Society of Industrial Vehicles in Algeria (SNVI), and the nominal composition of the as-received alloys was analyzed by X-ray Fluorescence Spectrometer (Philips Analytical Magi X-PROX).

The results, in weight percent, were, for Al-22\% Si : Fe 0.409, Si 21.871, Cu 0.081 , Mn 0.231, Ni 0.119, Zn 0.013, Pb 0.012, Ti 0.003 and the remainder Al; and for Al-20\% Mg: Fe 0.175, Si 0.307, Mg 19.849, Cu 0.218, Ni 0.013, Zn $0.008, \mathrm{~Pb} 0.020$ and balance $\mathrm{Al}$. The commercial pure aluminum has a purity of $99.99 \%$.

Annealing is needed to reach the physical-chemical equilibrium, and to improve mechanical properties. The ingots of $\mathrm{Al}-22 \% \mathrm{Si}$ and $\mathrm{Al}-20 \% \mathrm{Mg}$ were heattreated for $6 \mathrm{~h}$ at $520{ }^{\circ} \mathrm{C}$ in a muffle furnace, and cooled in water. The existing phases in the annealed alloys were identified using Philips X'PERT MPD X-ray diffractometer with a $\mathrm{Cu} \mathrm{K \alpha}$ radiation $(1.5406 \AA$ ).

The scan range was 5-100 2 -theta, with a step size of $0.02^{\circ}$ and a time per-step of 0.6 s. Their microstructures were observed and analyzed with scanning electron microscope (SEM JEOL JSM-7001F), using secondary electrons image, as well as EDX analysis.

\section{Electrochemical measurements}

For the electrochemical study, cylindrical specimens were cut from the heattreated ingots and embedded in epoxy resin. The cross section of the working electrodes $\left(1.538 \mathrm{~cm}^{2}\right.$ geometrical surface area) and that of the base metal $(0.385$ $\mathrm{cm}^{2}$ ) were mechanically ground with emery paper up to 1200 grit, degreased in acetone, rinsed with distilled water, dried and quickly transferred into an electrochemical cell filled with $100 \mathrm{~mL}$ of a $1 \mathrm{M} \mathrm{H}_{2} \mathrm{SO}_{4}$ solution.

The samples (working electrodes) corrosion behavior was evaluated in the temperature range from 10 to $50{ }^{\circ} \mathrm{C}$, using a continuously stirred $1 \mathrm{M} \mathrm{H}_{2} \mathrm{SO}_{4}$ solution, which was prepared by dilution of $98 \%$ analytical grade $\mathrm{H}_{2} \mathrm{SO}_{4}$ with 
distilled water. A saturated calomel electrode (SCE) as reference electrode and platinum foil as counter electrode were used, and all measured potentials were reported to this reference electrode. The electrochemical measurements were carried out using a Solartron Analytical 1287 potentiostat-galvanostat, and a 1260 Impedance/game phase Analyzer controlled by a computer.

Before each electrochemical test, the working electrode was immersed in the acidic solution at open circuit potential (OCP) for $0.5 \mathrm{~h}$, to attain a quasi-steady state. Potentiodynamic polarization curves were recorded by automatically varying the electrode potential in the cathodic-anodic direction from $-300 \mathrm{mV}$ vs. E $\mathrm{OCP}$ to $0 \mathrm{mV}$ vs. SCE, at a scan rate of $2 \mathrm{mV} \mathrm{s}^{-1}$. The plots were analyzed using Corrview software.

Electrochemical impedance spectroscopy (EIS) was carried out at OCP, in the frequency range from $10 \mathrm{mHz}$ to $100 \mathrm{kHz}$, with 10 points per decade, using a 10 $\mathrm{mV}$ peak-to-peak voltage excitation, and the diagrams analysis was done by ZPlot. The equivalent circuit models were fitted to the impedance data using Zview software.

Linear polarization resistance $\left(R_{p}\right)$ measurements were conducted at 0.166 $\mathrm{mVs}^{-1}$, with the scan in a potential range of $\pm 10 \mathrm{mV} / \mathrm{E}_{\text {corr }}$ (corrosion potential), to ensure the polarization curve linearity [29]. $R_{p}$ is defined as the polarization curve slope $(\mathrm{E}=\mathrm{f}(\mathrm{i}))$. The Stern-Geary equation [30] was employed to determine the corrosion current density, when the corrosion reaction was controlled by the activation process:

$$
\begin{gathered}
\mathrm{I}_{\text {corr }}=\frac{E}{R_{\mathrm{p}}} \\
B=\frac{b_{\mathrm{g}}\left|b_{\mathrm{g}}\right|}{2 \mathrm{a}\left(b_{\mathrm{g}}+\left|b_{\mathrm{c}}\right|\right)}
\end{gathered}
$$

where $b_{\mathrm{a}}$ and $b_{\mathrm{c}}$ are Tafel's anodic and cathodic coefficients.

When the cathodic curve presents the Tafel linear domain, and the anodic branch does not present any linear zone, the corrosion current density is evaluated by extrapolating the cathodic linear region back to the corrosion potential. The Stern -Geary formula becomes:

$$
\begin{gathered}
i_{\text {corr }}=\frac{\left|b_{c}\right|}{2.3 R_{p}} \\
B=\frac{\left|b_{E}\right|}{2.3}
\end{gathered}
$$

All the electrochemical tests were repeated at least thrice, to check measurements reproducibility.

\section{Results and discussion \\ SEM and XRD analysis}

SEM microstructures of the two annealed Al alloys are shown in Fig. 1.

The main crystalline phases of Al-22\%Si (Fig.1a) are characterized by primary silicon crystals surrounded by eutectic silicon-Al in $\alpha$ aluminum matrix. In order 
to reveal the eutectic silicon morphology, cast Al-22\% Si alloy etching was performed with a picral solution, for one minute. Many studies [20, 31-34] reported that the silicon's primary particles morphology depends on the casting process, cooling rates during melt solidification and on the silicon content. The primary silicon particles size was found to decrease with a rise in the cooling rate during solidification. According to Al-Mg system binary phase diagram [35] and SEM micrographs of the etched $\mathrm{Al}-20 \% \mathrm{Mg}$ alloy, its microstructure consists of a primary $\alpha$ - aluminum dendrites phase and an eutectic matrix, which is a mixture of $\beta$ - $\mathrm{Al}_{3} \mathrm{Mg}_{2}$ and $\alpha$ - aluminum solid phase (Fig. 1b ). Similar microstructure morphology was reported by O. Fakhraei et al., for a binary Al$20 \% \mathrm{Mg}$ alloy $[23,36]$.
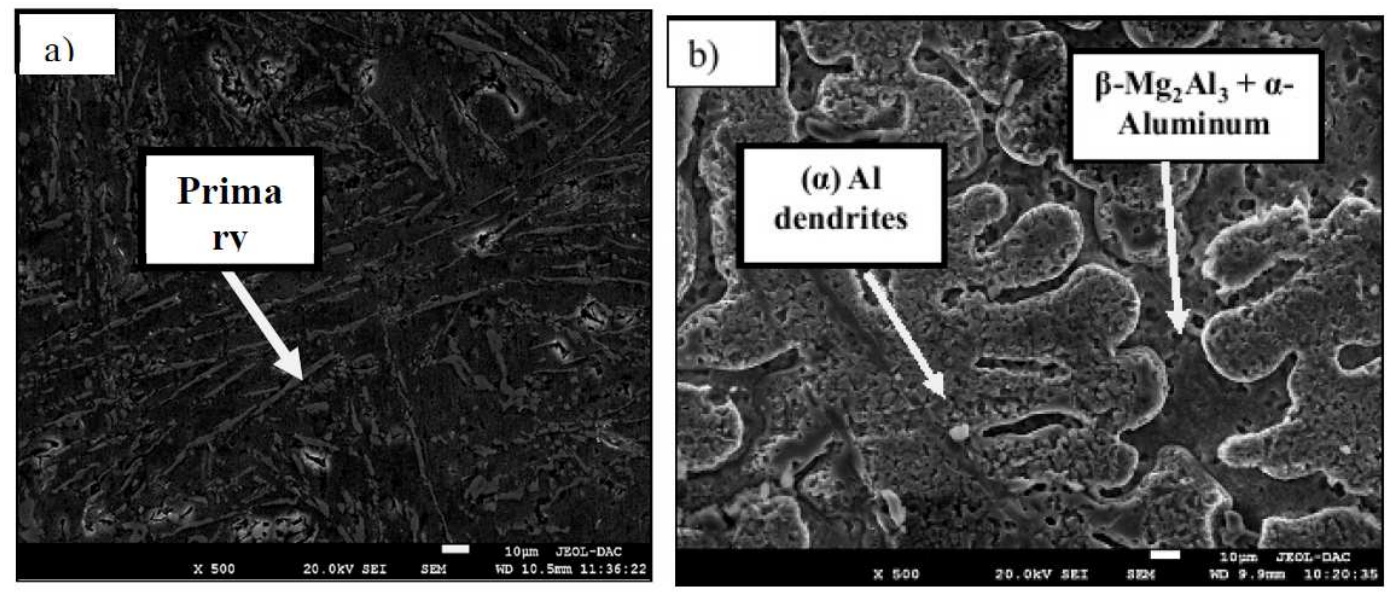

Figure 1. SEM pictures of etched a) Al-22\% Si and b) Al-20\%Mg.
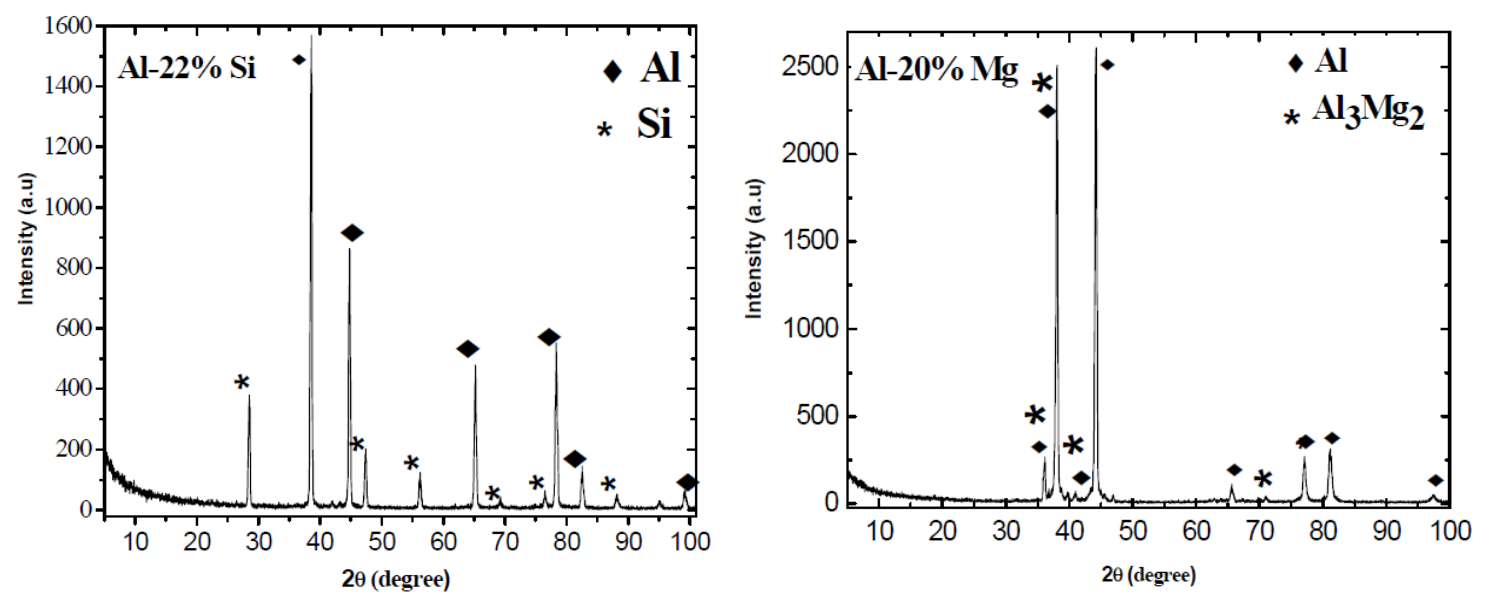

Figure 2. XRD pattern of the two heat-treated Al-alloys.

These results are in accordance with the XRD pattern of the two heat-treated alloys (Fig. 2).

\section{Electrochemical and spontaneous corrosion}

\section{Evolution of the OCP during the immersion test}

The open circuit potential evolution with immersion time is the parameter that provides the first information about changes occurred at the interface 
metal/solution. As seen in Fig. 3, at the immersion beginning, OCP rapidly shifts to the anodic values, reaching a quasi-steady-state after $4 \mathrm{~h}$ of immersion. This evolution indicates that the metal surface is covered with a film which could be composed by the corrosion product and/or oxides.

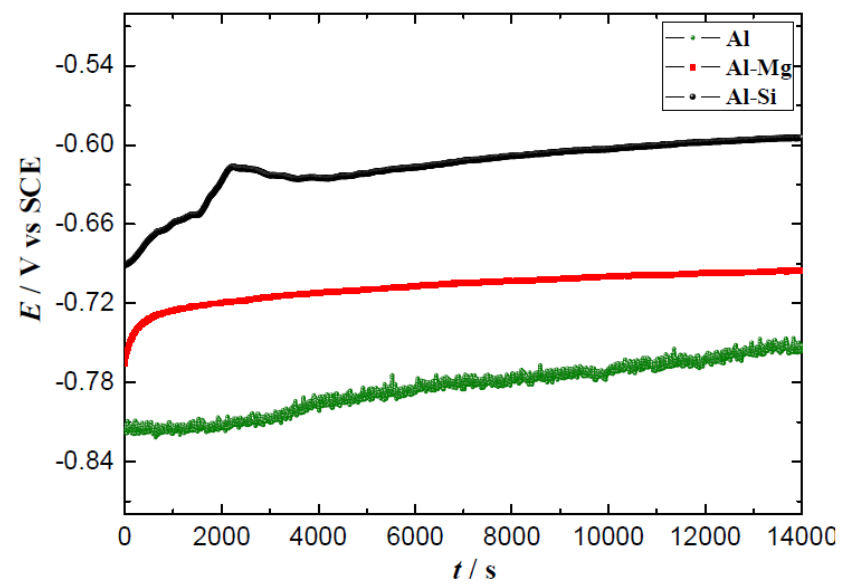

Figure 3. Open circuit potential of the three $\mathrm{Al}$ samples in $1 \mathrm{M} \mathrm{H}_{2} \mathrm{SO}_{4}$ at $20{ }^{\circ} \mathrm{C}$.

The pre-immersion air-formed oxide film $\left(\mathrm{Al}_{2} \mathrm{O}_{3}\right)$ can exist in an acidic solution [14], and its stability depends on the anions' effect, rather than on the solution's $\mathrm{pH}$ [37]. It is worthy to note that Pourbaix diagram [38] does not mention the existence of this oxide in the $\mathrm{pH}$ range below 4 . However, during corrosion, the $\mathrm{pH}$ can locally increase at the metal/ solution interface, leading to the formation of metallic hydroxides and metallic oxides.

We note that $\mathrm{Al}-22 \% \mathrm{Si}$ has the nobler open circuit potential value, but pure $\mathrm{Al}$ and $\mathrm{Al}-20 \% \mathrm{Mg}$ present open circuit potentials which are close to each other. This result can be correlated with the two alloys microstructure: the primary $\mathrm{Si}$ phase of $\mathrm{Al}-22 \% \mathrm{Si}$ is cathodic [20], whereas the intermetallic $\beta-\mathrm{Al}_{3} \mathrm{Mg}_{2}$ in $\mathrm{Al}$ $20 \% \mathrm{Mg}$ is anodic, in respect to the Al-based matrix. Besides, this intermetallic phase is known to be quite active in acidic media [27].

\section{Potentiodynamic polarization curves and linear polarization resistance (LPR)} at $20^{\circ} \mathrm{C}$

Fig. 4a shows potentiodynamic polarization curves of the three electrochemical systems at $20^{\circ} \mathrm{C}$. 

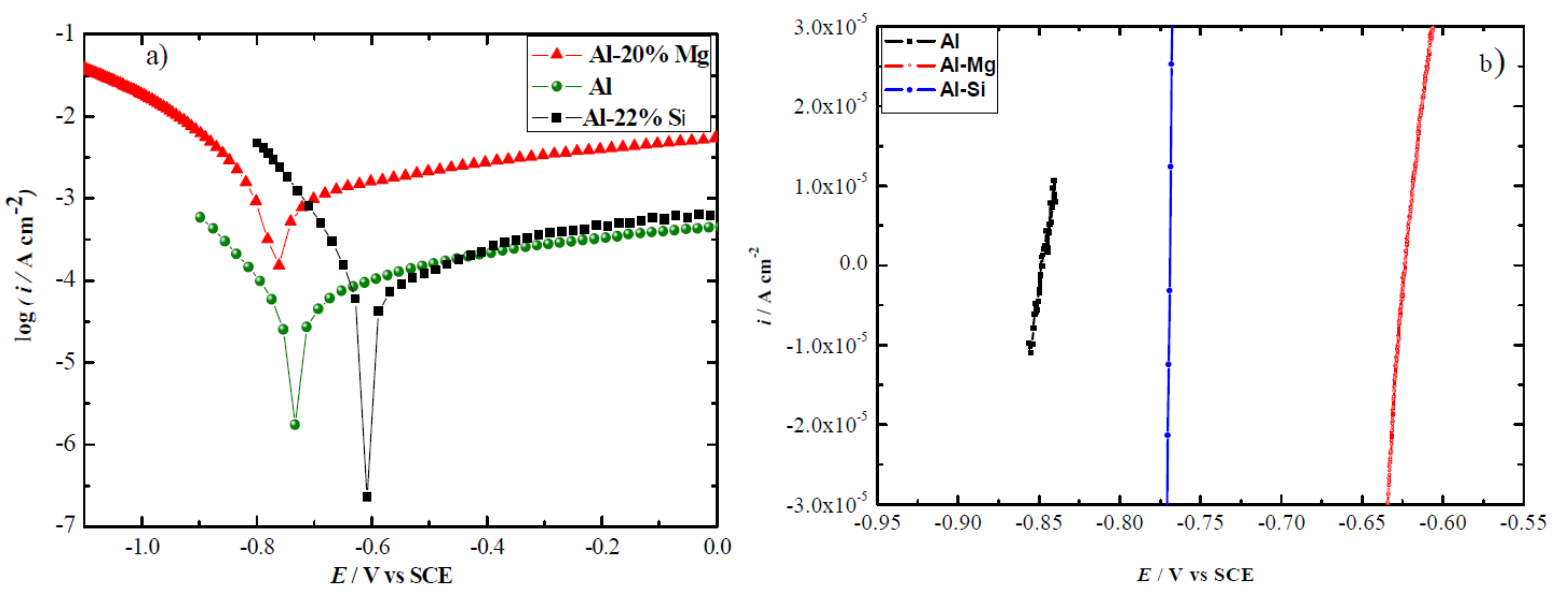

Figure 4. a) Potentiodynamic polarization curves at a scan rate of $2 \mathrm{mV} \mathrm{s}^{-1}$, b) LPR at a scan rate of $0.166 \mathrm{mV} \mathrm{s}^{-1}$.

The cathodic branches are characterized by parallel Tafel lines, indicating that the hydrogen evolution reaction (HER) is governed by an activation process [39], in an aerated $1 \mathrm{M} \mathrm{H}_{2} \mathrm{SO}_{4}$ solution. It should be noticed that, even if the acid solution is aerated, HER is the principal reaction in addition to oxygen's reduction [40]. The studied working electrodes' nature does not modify the reduction reaction mechanism.

Table 1. Electrochemical parameters deduced by Tafel and LPR methods for the three samples in $1 \mathrm{M} \mathrm{H}_{2} \mathrm{SO}_{4}$, at different temperatures.

\begin{tabular}{|c|c|c|c|c|c|c|c|}
\hline \multicolumn{4}{|c|}{ Tafel method } & \multicolumn{4}{|c|}{ LPR method } \\
\hline 莺 & $\begin{array}{l}\mathrm{T} / \\
{ }^{\circ} \mathrm{C}\end{array}$ & $\begin{array}{c}-E_{\text {corr }} / \\
\mathrm{mV} / \mathrm{SCE}\end{array}$ & $\begin{array}{c}i_{\text {corr }} / \\
\mathbf{m A ~} \mathbf{c m}^{-2}\end{array}$ & $\begin{array}{c}-E_{\text {corr }} / \\
\mathrm{mV} / \mathrm{SCE}\end{array}$ & $\begin{array}{c}B \\
\mathrm{mV} / \mathrm{dec}\end{array}$ & $\begin{array}{c}R p / \\
\Omega \mathrm{cm}^{2}\end{array}$ & $\begin{array}{c}i_{\text {corr }} / \\
\mathbf{m A ~} \mathbf{c m}^{-2}\end{array}$ \\
\hline \multirow{5}{*}{ 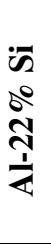 } & 10 & 622.81 & 0.0229 & 638.77 & 36.496 & 807.67 & 0.0452 \\
\hline & 20 & 611.45 & 0.0537 & 640.05 & 38.790 & 401.63 & 0.0965 \\
\hline & 30 & 615.30 & 0.0972 & 705.50 & 41.430 & 203.53 & 0.1822 \\
\hline & 40 & 621.23 & 0.1935 & 699.41 & 38.746 & 121.45 & 0.3191 \\
\hline & 50 & 621.58 & 0.3369 & 688.29 & 41.647 & 76.394 & 0.5452 \\
\hline \multirow{5}{*}{$\begin{array}{l}\sum_{2}^{00} \\
0 \\
0 \\
\frac{7}{2} \\
\frac{1}{4}\end{array}$} & 10 & 772.79 & 0.4089 & 760.04 & 57.669 & 111.76 & 0.5161 \\
\hline & 20 & 773.27 & 0.8451 & 769.04 & 62.495 & 52.794 & 1.1837 \\
\hline & 30 & 747.76 & 1.8670 & 757.79 & 76.121 & 31.178 & 2.4415 \\
\hline & 40 & 760.37 & 3.6398 & 758.28 & 77.860 & 14.386 & 5.4122 \\
\hline & 50 & 764.15 & 7.0038 & 767.89 & 89.682 & 7.3798 & 12.1524 \\
\hline Z & 20 & 789.10 & 0.0468 & 804 & 50.26 & 776.75 & 0.0647 \\
\hline
\end{tabular}

The anodic polarization curves of the three samples exhibit a gradual increase in the current density with the increase in potential. Beyond a certain anodic potential value, the current variation becomes potential independent. P. Schmuki attributed this typical behavior to a non-passive state where a metal dissolution occurs through a salt layer [12]. Similar electrochemical behavior was reported 
for aluminum in $\mathrm{H}_{2} \mathrm{SO}_{4}$ [41-42]. Nevertheless, F. Holzer et al. stated that aluminum and its alloys cannot be activated in sulfuric acid, due to the strongly passivating character of this electrolyte [43]. The anodic current densities values related to $\mathrm{Al}-20 \% \mathrm{Mg}$ are considerably high; this phenomenon can be assigned to the $\beta-\mathrm{Al}_{3} \mathrm{Mg}_{2}$ active dissolution, which populates its microstructure. This intermetallic phase is described as an anodic phase [27, 44-45], whilst the Al matrix represents the cathodic area on which the reduction reaction takes place. M. Liu et al. [28] stated that this phase undergoes magnesium selective dissolution in a $\mathrm{Na}_{2} \mathrm{SO}_{4}$ solution, because $\mathrm{Mg}$ is the most active element. In the current study, since the Al-Mg alloy anodic behavior is different from that of pure Al and Al-Si alloy, we can suggest that the same phenomenon of selective dealloying occurs in the $\mathrm{Al}-20 \% \mathrm{Mg}$ sample which contains the $\beta-\mathrm{Al}_{3} \mathrm{Mg}_{2}$ phase. The anodic branches of the silicon alloy and those of pure Al are very close to each other. These electrochemical behaviors could be correlated to the microstructure of these alloys. Indeed, it is reported in the literature [20] that, in $\mathrm{Al}-\mathrm{Si}$ alloys, the silicon primary phase is cathodic, while the aluminum matrix is an anodic phase. This can be explained by the standard potential values of the two chemical elements, since silicon is nobler than aluminum. Consequently, the anodic dissolution can be attributed to the $\mathrm{Al}^{3+}$ cations released from the $\mathrm{Al}$ matrix, whereas the reduction process occurs on the cathodic primary silicon phase. The electrochemical parameters deduced by the Tafel method are gathered in Table 1.

These results show that $\mathrm{Al}-\mathrm{Si}\left(53.75 \mu \mathrm{A} \mathrm{cm} \mathrm{cm}^{-2}\right)$ and $\mathrm{Al}\left(46.82 \mu \mathrm{A} \mathrm{cm} \mathrm{cm}^{-2}\right)$ corrosion current densities are in the same magnitude order, confirming the similarity of their anodic behavior. However, Al-Mg alloy corrosion rate value is much higher $\left(845.09 \mu \mathrm{A} \mathrm{cm}^{-2}\right)$, indicating that this alloy is the most significantly corroded in $1 \mathrm{M} \mathrm{H}_{2} \mathrm{SO}_{4}$. The corrosion potential and the corrosion rate do not have the same trend; this attests that the corrosion potential is the metallic corrosion criterion.

The linear polarization curves (Fig. 4b), for the studied samples, are represented by straight lines, highlighting the linearity between the current density and the potential. This proportional variation is well described by the Stern equation, which allows the determination of the polarization resistance values.

The electrochemical parameters measured by the linear polarization technique are illustrated in Table 1.

The reported values are in agreement with those obtained from the Tafel method, and the variation of $\mathrm{i}_{\text {corr }}$ and $\mathrm{E}_{\text {corr }}$ is given as follows:

$\mathrm{E}_{\text {corr }}(\mathrm{Al}-22 \% \mathrm{Si})>\mathrm{E}_{\text {corr }}(\mathrm{Al}-20 \% \mathrm{Mg})>\mathrm{E}_{\text {corr }}(\mathrm{Al})$, and $\mathrm{R}_{\mathrm{p}}(\mathrm{Al})>\mathrm{R}_{\mathrm{p}}(\mathrm{Al}-22 \% \mathrm{Si})$ $>\mathrm{R}_{\mathrm{p}}(\mathrm{Al}-20 \% \mathrm{Mg})$.

It can be confirmed that $\mathrm{i}_{\text {corr }}$ is inversely proportional to $\mathrm{R}_{\mathrm{P}}$ as: $\mathrm{i}_{\text {corr }}(\mathrm{Al}-20 \% \mathrm{Mg})$ $>\mathrm{i}_{\text {corr }}(\mathrm{Al}-22 \% \mathrm{Si})>\mathrm{i}_{\text {corr }}(\mathrm{Al})$.

\section{Electrochemical impedance spectroscopy at $20^{\circ} \mathrm{C}$}

The typical Nyquist representations for pure aluminum, Al-22\% Si and Al-20\% $\mathrm{Mg}$, in a $1 \mathrm{M}$ sulfuric acid solution at $20{ }^{\circ} \mathrm{C}$, are illustrated in Fig. 5.The base 
metal and silicon alloy plots have identical shapes. This indicates that the two working electrodes have similar electrochemical corrosion behaviors.

It is noticed that EIS diagrams are characterized by a single depressed semicircle, in the whole frequencies domain, with the center under the real axis. This behavior characterizes the impedance data of metal electrodes that show frequencies dispersion [46]. This phenomenon is generally related to porosities and heterogeneousness on the metal surface [47]. The well-defined capacitive semicircles suggest that the corrosion process is governed by a pure activation mode [48]. It is very difficult to get an aluminum surface free from an oxide film, due to its high reactivity with oxygen [49-50]. Therefore, it is reasonable to admit the formation of an oxide on aluminum and Al-22\% Si alloy in the sulfuric acid solution, since it was proven that $\mathrm{SO}_{4}^{2-}$ ions are not very aggressive for aluminum, even if the $\mathrm{pH}$ is low $[37,43,51]$. We can thus assign the capacitive loop to the global oxidation process of the base metal and of the silicon alloy at the metal/oxide/ $\mathrm{H}_{2} \mathrm{SO}_{4}$ interface. Since the aluminum matrix constitutes the anodic phase, while the primary silicon is the cathodic one, it can be assumed that aluminum dissolution occurs as follows: first, there is the formation of $\mathrm{Al}^{+}$ ions at the metal/oxide interface (we can admit the existence of this oxide, because we have previously observed an OCP ennoblement); then, they migrate through the oxide/ $\mathrm{H}_{2} \mathrm{SO}_{4}$ interface; and finally, they oxidize to $\mathrm{Al}^{3+}$. This mechanism is proposed by Brett for aluminum in an acidic solution [51].
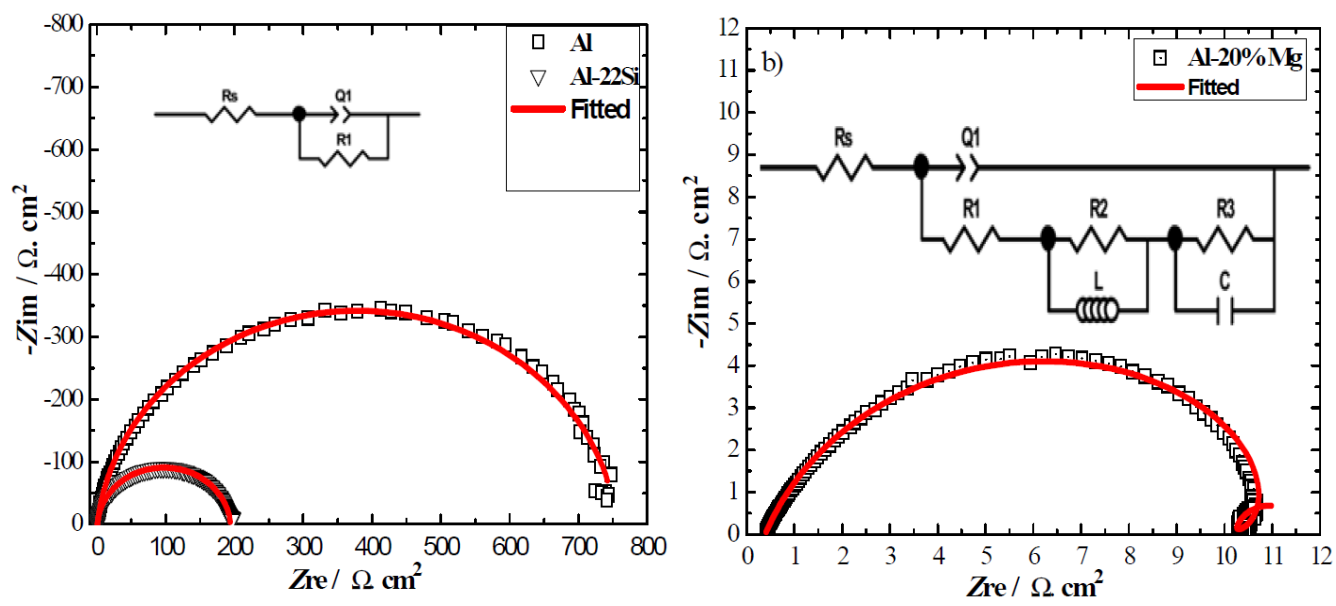

Figure 5. EIS diagrams for the three materials immersed in $1 \mathrm{M} \mathrm{H}_{2} \mathrm{SO}_{4}$, at $20{ }^{\circ} \mathrm{C}$.

The reason for the appearance of one capacitive loop characterizing all these processes is the existence of one determinant step that hides the others [52].

As it is observed, the impedance diagram shape of $\mathrm{Al}-20 \% \mathrm{Mg}$ alloy is represented by three time constants, namely: (i) a large capacitive loop at high frequencies (HFs); (ii) a small inductive loop at medium frequencies (MFs); and (iii) a second capacitive loop at low frequencies (LFs). A similar phenomenon is observed for aluminum in $\mathrm{H}_{2} \mathrm{SO}_{4}$ [41-53]. According to the electrochemical results previously obtained, we can attribute the magnesium alloy corrosion to the $\beta-\mathrm{Al}_{3} \mathrm{Mg}_{2}$ phase dealloying occurred by the active $\mathrm{Mg}$ element selective dissolution. Therefore, we assume that the overall $\mathrm{Mg}$ oxidation reaction can be summarized as follows: in the beginning, there is the formation of the 
intermediate $\mathrm{Mg}^{+}$ions at the metal /oxide interface; then, their diffusion through the oxide/ $\mathrm{H}_{2} \mathrm{SO}_{4}$ interface, and their subsequent oxidation to $\mathrm{Mg}^{2+}$. G. Song [5455] reported the formation of a monovalent $\mathrm{Mg}$ ion. All these observations led us to assign the capacitive semicircle at high frequencies to the formation of an univalent $\mathrm{Mg}^{+}$magnesium ion by an electrochemical reaction, since it was assumed to be the rate determining step of the $\mathrm{Mg}$ dissolution [55]. The first capacitive loop is related to the charge transfer of the corrosion process and to the double layer behavior [56]. In its turn, the second capacitive loop, corresponding to the low frequencies, could be ascribed to the chemical oxidation reaction of $\mathrm{Mg}^{+}$with water, to produce a divalent $\mathrm{Mg}^{2+}$ ion (faster step) and hydrogen. The inductive time constant at medium frequencies is often attributed to surface or bulk relaxation of the species in the oxide [57]. Intermediates adsorption, such as $\mathrm{H}^{+}, \mathrm{SO}_{4}^{2-}$ ions or $\mathrm{O}^{2-}$, could also cause an inductive loop [58]. One can observe that the inductive loop appears in the negative part of the complex diagram, instead of appearing below the real axis, as it is the case for a pure inductance; the same phenomenon was observed by $\mathrm{X}$. $\mathrm{Li}$ et al., for aluminum in $1 \mathrm{M} \mathrm{H}_{3} \mathrm{PO}_{4}$ [56]. No convincing explanation can be provided, because the alloys dissolution mechanism is very complex.

Two equivalent circuits were used to analyze the impedance spectra of the three samples; they are inserted in Fig. 5. The equivalent circuit corresponding to pure $\mathrm{Al}$ and silicon alloy consists of three elements: solution resistance $\left(\mathrm{R}_{\mathrm{S}}\right)$, and charge transfer resistance $\left(\mathrm{R}_{1}\right)$, in parallel with the constant phase element (CPE) defined by the $\mathrm{Q}_{1}$ parameter. The $\mathrm{Mg}$ alloy's equivalent circuit comprises seven elements: solution resistance $\left(R_{S}\right)$, charge transfer resistance $\left(R_{1}\right)$, in parallel with a constant phase element (CPE), represented by the $\mathrm{Q}_{1}$ coefficient, assigned to the capacitive loop at HFs, $L$ inductance in parallel with $\mathrm{R}_{2}$ inductance resistance, corresponding to $\mathrm{MFs}$, and a $\mathrm{C}$ double layer capacitance, in parallel with a $\mathrm{R}_{3}$ resistance, simulating the capacitive loop at LFs. Note that the same electric circuit has been used by A. Saviour et al. [53], for aluminum in $0.5 \mathrm{M} \mathrm{H}_{2} \mathrm{SO}_{4}$. It should be pointed out that some authors failed to model such an interface; so, they focused their study only on the high frequencies loop corresponding to the charge transfer process [56]. CPE is used in the equivalent circuit, instead of pure capacitance, to fit more accurately the EIS diagrams. CPE impedance is defined by the following relation [59-61]:

$$
Z(\mathrm{j} \omega)=\ell_{1}^{-1}(\mathrm{j} \omega)^{-\mathrm{n}}
$$

where $\mathrm{Q}_{1}$ is the CPE parameter, $\mathrm{j}$ is the imaginary unit, $\omega$ is the angular frequency ( $\omega=2 \pi \mathrm{f}$, $\mathrm{f}$ is the frequency) and the CPE exponent that can assume the following values: 1 (pure capacitance), 0.5 (Warburg diffusion), 0 (resistance) and -1 (inductance) [62]. CPE is generally believed to originate from the distribution in the current density along the electrode's surface, as a result of the electrode roughness and inhomogeneity. This can be inferred from the analogy with the behavior of porous electrodes [63].

Table 2 shows the deduced EIS parameters for the three aluminum samples in a 1 $\mathrm{M} \mathrm{H}_{2} \mathrm{SO}_{4}$ solution at $20^{\circ} \mathrm{C}$. These parameters have been obtained after fitting the experimental data. 
Constant phase element (CPE) is used to describe the double layer at the metal/solution interface, which is characterized by a non-ideal capacitive behavior. The double layer capacitance $\left(\mathrm{C}_{\mathrm{dl}}\right)$ values were deduced from $C P E\left(\mathrm{Q}_{1}\right)$ elements, using the following equation [64]:

$$
C_{\mathrm{dl}}=Q_{1} \times\left(2 \pi f_{\max }\right)^{\mathrm{n}-1}
$$

where $f_{\max }$ is the frequency that corresponds to the maximal value of the impedance imaginary part $\left(-Z_{\mathrm{im}}\right)$ on the Nyquist diagram.

As it can be seen in Fig 5a-b, there is a good agreement between the fitting data (in red) and experimental data (in black). The chi-squared $\left(\chi^{2}\right)$ was employed to select the better fit.

Table 2. EIS parameters for the three aluminum materials immersed in $1 \mathrm{M} \mathrm{H}_{2} \mathrm{SO}_{4}$ at different temperatures.

\begin{tabular}{|c|c|c|c|c|c|c|c|c|c|c|c|}
\hline Samples & $\begin{array}{l}\mathrm{T} / \\
{ }^{\circ} \mathrm{C}\end{array}$ & $\begin{array}{c}R \mathrm{~s} / \\
\Omega \mathrm{cm}^{2}\end{array}$ & $\begin{array}{c}Q_{1} / \\
\mathrm{m} \Omega^{-1} \mathbf{c m}^{-2} \mathbf{s}^{-n}\end{array}$ & $\begin{array}{c}C_{\mathrm{dl}} / \\
\mathrm{mF} \mathrm{cm}^{-2}\end{array}$ & $\mathbf{n}$ & $\begin{array}{c}R_{1} / \\
\Omega \mathrm{cm}^{2}\end{array}$ & $\begin{array}{c}R_{2} / \\
\Omega \mathrm{cm}^{2}\end{array}$ & $\begin{array}{c}L / \\
\mathrm{H} \mathrm{cm}{ }^{2}\end{array}$ & $\begin{array}{c}R_{3} / \\
\Omega \mathrm{cm}^{2}\end{array}$ & 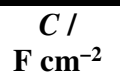 & $\chi^{2}$ \\
\hline \multirow{5}{*}{ 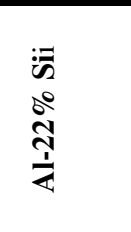 } & 10 & 0.897 & 0.085 & 0.068 & 0.928 & 611.70 & - & - & - & - & $6.0 \times 10^{-3}$ \\
\hline & 20 & 0.793 & 0.0870 & 0.063 & 0.929 & 189.90 & - & - & - & - & $4.9 \times 10^{-3}$ \\
\hline & 30 & 0.749 & 0.099 & 0.068 & 0.927 & 83.29 & - & - & - & - & $1.2 \times 10^{-3}$ \\
\hline & 40 & 0.625 & 0.100 & 0.062 & 0.915 & 48.49 & - & - & - & - & $1.6 \times 10^{-3}$ \\
\hline & 50 & 0.500 & 0.119 & 0.063 & 0.898 & 28.53 & - & - & - & - & $2.2 \times 10^{-3}$ \\
\hline \multirow{5}{*}{$\begin{array}{l}\sum_{20}^{\infty} \\
\vdots \\
\stackrel{-}{1} \\
\frac{1}{2}\end{array}$} & 10 & 0.441 & 1.300 & 0.473 & 0.769 & 25.90 & 9.658 & 0.5900 & 4.18 & 4.895 & $4.1 \times 10^{-3}$ \\
\hline & 20 & 0.389 & 1.127 & 0.300 & 0.773 & 9.96 & 1.970 & 0.0600 & 0.87 & 1.439 & $2.8 \times 10^{-3}$ \\
\hline & 30 & 0.360 & 0.875 & 0.305 & 0.808 & 4.31 & 0.520 & 0.0100 & 0.52 & 0.102 & $2.9 \times 10^{-3}$ \\
\hline & 40 & 0.339 & 0.773 & 0.312 & 0.877 & 1.69 & 0.147 & 0.0012 & 0.51 & 0.014 & $1.7 \times 10^{-3}$ \\
\hline & 50 & 0.324 & 0.689 & 0.333 & 0.910 & 0.81 & 0.053 & 0.0003 & 0.24 & 0.004 & $2.0 \times 10^{-3}$ \\
\hline Z & 20 & 1.015 & 0.072 & 0.014 & 0.940 & 754.8 & & - & - & - & $7.4 \times 10^{-4}$ \\
\hline
\end{tabular}

Indeed, Table 2 reveals that $\chi^{2}$ values are very low, showing that the selected electrical circuits are the most appropriate to simulate the phenomenon occurring at the metal/solution interface.

Inspection of Table 2 reveals that aluminum charge transfer resistance $\left(R_{1}\right)$ value is the highest one $\left(754.80 \Omega \mathrm{cm}^{2}\right)$, whilst that of Al-20\% $\mathrm{Mg}$ alloy is the lowest $\left(9.96 \Omega \mathrm{cm}^{2}\right)$. Since that charge transfer resistance is inversely proportional to the corrosion current density, the magnesium alloy undergoes the most intense dissolution in the studied acid solution. The CPE exponent $\mathrm{n}$ value of this alloy is about 0.773 , describing the deviation from ideal capacitance. This phenomenon can be related to heterogeneities on the alloy's surface, due to the corrosion products precipitation or to the porosities. The large $\mathrm{CPE}\left(\mathrm{Q}_{1}\right)$ parameter value $\left(1.127 \mathrm{~m} \Omega \mathrm{cm}^{-2} \mathrm{~s}^{-\mathrm{n}}\right)$ corresponding to the $\mathrm{Al}-20 \% \mathrm{Mg}$ alloy may be attributed to a very charged and conducted alloy/solution interface [65], which originates from the emergence of numerous active sites generated by electrochemical reactions; this is a characteristic of the strongly corroded surface. Furthermore, the capacitance value is equal to $0.3 \mathrm{mF} \mathrm{cm}^{-2}$, clearly exceeding the magnitude order of the double layer capacitance values, which must be, at most, equal to a 
few tens of $\mu \mathrm{F} \mathrm{cm}^{-2}$ [66-67], as it is the case for those of $\mathrm{Al}\left(14 \mu \mathrm{F} \mathrm{cm} \mathrm{cm}^{-2}\right)$ and Al-22\% Si $\left(63 \mu \mathrm{F} \mathrm{cm}^{-2}\right)$.

Corrosion morphology of the two aluminum alloys

Fig. 6 shows the SEM images of the corroded Al-alloys, after their immersion for two days in sulfuric acid. Examination of Al-22\% Si micrograph (Fig.6a) reveals a corrosion attack on the Al matrix and eutectic Al-Si phase, as they represent the anodic sites surrounding an unattacked cathodic primary silicon phase. A similar result was found by A. Mazhar et al. for Al-22\% Si exposed to $\mathrm{HCl} 0.25 \mathrm{M}$ [10]. The anodic phase dissolution leads to a better highlight of the cathodic coarse primary silicon crystals (in black). All these features are confirmed by the results deduced from the potentiodynamic polarization curves (Fig. 4).
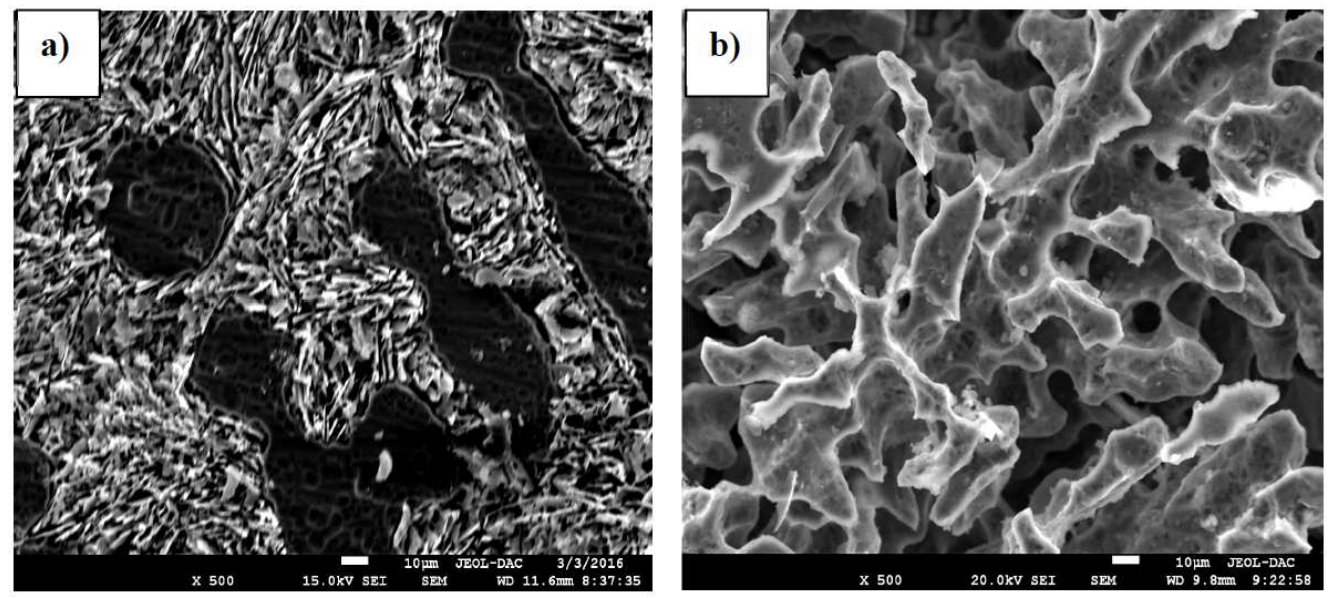

Figure 6. SEM pictures after immersion for 2 days in $1 \mathrm{M} \mathrm{H}_{2} \mathrm{SO}_{4}$ for a) $\mathrm{Al}-22 \% \mathrm{Si}$ and b) $\mathrm{Al}-20 \% \mathrm{Mg}$.

On the other hand, one can see in the magnified image (Fig. 6b) that Al-20\% Mg undergoes severe damage in the eutectic matrix composed by the intermetallic $\beta$ $\mathrm{Al}_{3} \mathrm{Mg}_{2}$ and $\alpha$-Al. Indeed, it was reported [27] that the $\beta-\mathrm{Al}_{3} \mathrm{Mg}_{2}$ phase which populates Al-Mg alloys is responsible for their dissolution in the acidic solution by its dealloying. This phenomenon is highlighted in Fig.6b by the large spaces or voids between the dendrite arms, caused by the intermetallic $\beta$ - $\mathrm{Al}_{3} \mathrm{Mg}_{2}$ phase dissolution. This observation is in accordance with the high capacitance value deduced by the EIS method.

All these observations confirm the electrochemical results that revealed a weak corrosion resistance of the $\mathrm{Al}-20 \% \mathrm{Mg}$ alloy in a sulfuric acid solution.

\section{Temperature effect on the electrochemical behavior of the two Al-alloys}

To further investigate the corrosion resistance of the two aluminum alloys in a 1 $\mathrm{M} \mathrm{H}_{2} \mathrm{SO}_{4}$ solution, we have examined the temperature effect on their electrochemical behavior, in the range from 10 to $50{ }^{\circ} \mathrm{C}$. Potentiodynamic polarization curves of the two samples, at various temperatures in $1 \mathrm{M} \mathrm{H}_{2} \mathrm{SO}_{4}$, are depicted in Fig. 7. 

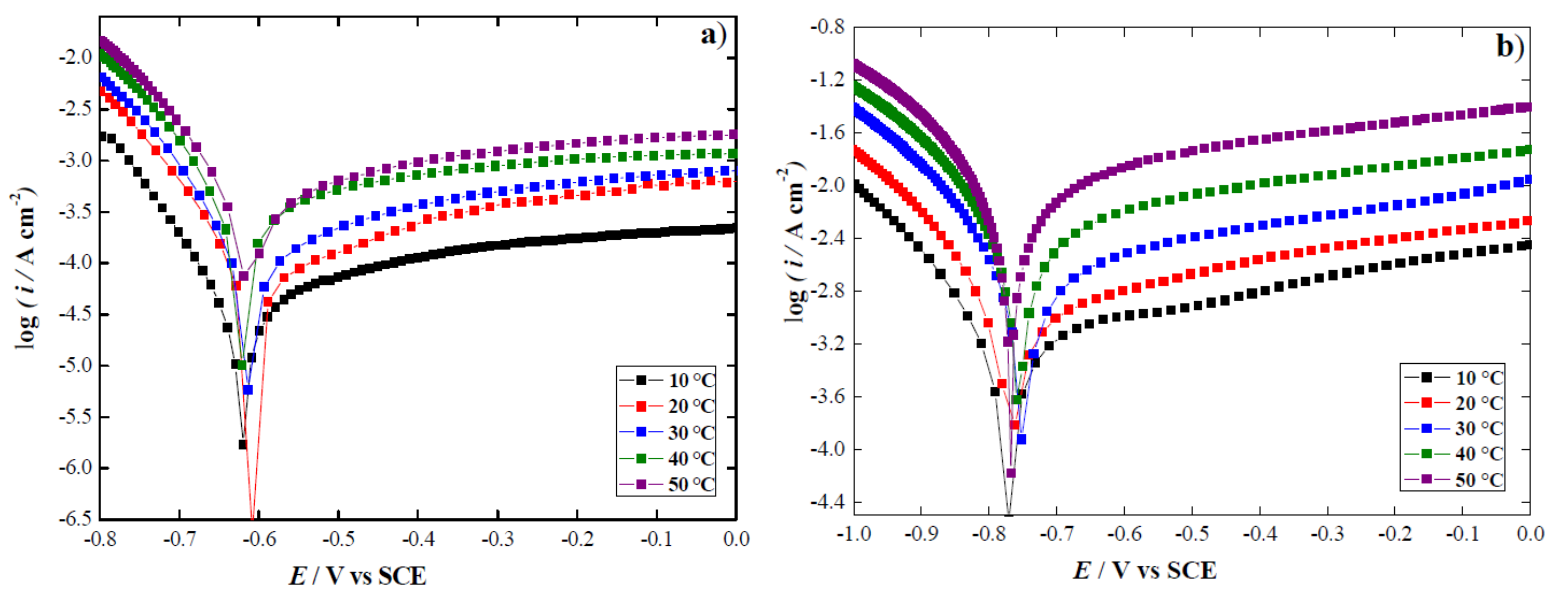

Figure 7. Temperature effect on the potentiodynamic polarization curves of: a) Al-22\% $\mathrm{Si}$ and b) $\mathrm{Al}-20 \% \mathrm{Mg}$, at the scan rate of $2 \mathrm{mV} \mathrm{s}^{-1}$.

It is obvious that the polarization curves shape is not affected by an increase in temperature, meaning that the electrode processes are not modified. However, theses curves are translated towards the current densities highest values, when temperature rises. This can be related to the acceleration of anodic and cathodic reactions. Corrosion potentials and corrosion current densities values of the alloys are given in Table 1. As expected, their corrosion current densities are temperature dependent, so, they are increased to high values with the rise in temperature. However, it was observed that $\mathrm{Al}-22 \% \mathrm{Si}$ corrosion rate at $50{ }^{\circ} \mathrm{C}$ $\left(0.337 \mathrm{~mA} \mathrm{~cm}^{-2}\right)$ is lower than $\mathrm{Al}-20 \% \mathrm{Mg}\left(0.409 \mathrm{~mA} \mathrm{~cm}{ }^{-2}\right)$ corrosion current density at $10^{\circ} \mathrm{C}$. This confirms the vulnerability of the magnesium alloy in sulfuric acid. On the contrary, a slight variation of the corrosion potential was recorded when the temperature increased, in both cases.

The influence of temperature on the linear polarization curves was examined for each studied alloy. The obtained electrochemical parameters for all temperatures are summarized in Table 1. The main result is that corrosion current densities values increase with an increase in temperature, whereas polarization resistance values decrease. This fact indicates that $\mathrm{Al}$ alloys corrosion behavior deteriorates with the rise in temperature.

EIS spectra of the two electrochemical systems were recorded in the temperature range from 10 to $50^{\circ} \mathrm{C}$, and are shown in Figs.8a-b.

At this figure, the shape of Nyquist complex diagrams remains unchanged as temperature increases, suggesting that similar dissolution mechanisms occurred in $1 \mathrm{M} \mathrm{H}_{2} \mathrm{SO}_{4}$ at the two interfaces. Inspection of these plots also revealed that, as temperature raised, semicircles size continuously decreased, which indicates the metallic dissolution acceleration. Calculated EIS parameters are given in Table 2. It is well-known that the Nyquist plot intersection with the real axis at high frequencies $(f \rightarrow \infty)$ represents the solution resistance $\left(\mathrm{R}_{\mathrm{s}}\right)$ enclosed between working electrode and reference electrode. The two systems' $\mathrm{R}_{\mathrm{s}}$ data are reduced as temperature rises, which indicates that metallic dissolution is accelerated, leading to a decrease in the ohmic drop $\left(R_{s}\right)$. Moreover, it was also shown that these values are lower than $1 \Omega \mathrm{cm}^{2}$, which means that the solution conductivity in the working electrode vicinity is very high. The increase in the conductivity 
with the rise in temperature could be related to the solution enrichment by ionic conductors, which are constituted by the metallic ions.

Analysis of the increased temperature effect on the charge transfer resistance $\left(R_{\mathrm{t}}\right)$ value of the alloys, which was reduced, reveals that it decreased the alloys corrosion resistance. In contrast, the capacitance $\left(C_{\mathrm{dl}}\right)$ values did not suffer a remarkable increase; this means that the corrosion products did not change the double layer structure [64].

The high capacitance (C) values, corresponding to the Al-Mg alloy lowfrequencies capacitive loop, suggest that they are pseudo capacitances. The same phenomenon has been reported by D. Pavlov et al. [68], when studying Sb anodic dissolution in a sulfuric acid solution. These authors explain this feature by the layer adsorption onto the electrode surface. Inspection of the capacitance data (Table 2) shows that, although they were high, they underwent a clear drop in the range of $10^{\circ} \mathrm{C}$ to $50^{\circ} \mathrm{C}$. To explain this phenomenon, it can be suggested that, at low temperatures $\left(10^{\circ} \mathrm{C}\right.$ and $\left.20^{\circ} \mathrm{C}\right)$, corrosion products adhere to the metal surface, increasing its activity, whereas at higher temperatures, they leave the metal surface and pass into the acidic solution.
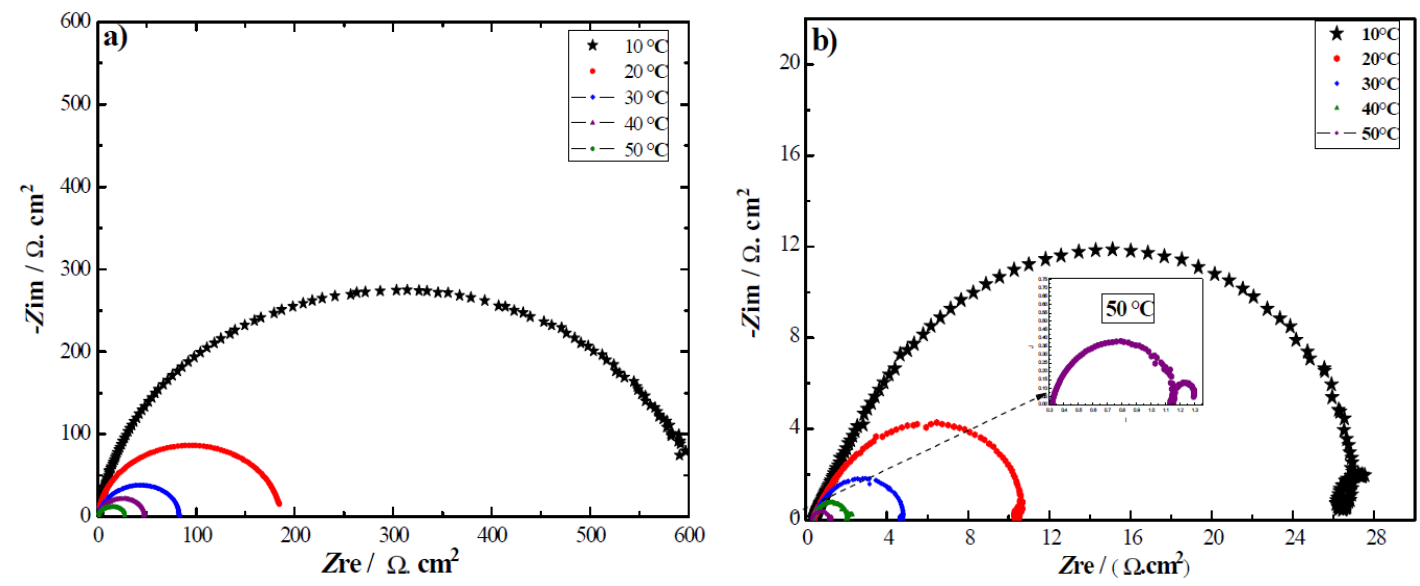

Figure 8. Temperature effect on EIS diagrams of a) $\mathrm{Al}-22 \% \mathrm{Si}$ and b) $\mathrm{Al}-20 \% \mathrm{Mg}$ in 1 $\mathrm{M} \mathrm{H}_{2} \mathrm{SO}_{4}$

\section{Arrhenius law}

It was experimentally found that most of the reaction rates in the solution exponentially varied with temperature; the same is true for corrosion current densities [67]. The Arrhenius equation is used to describe this relation:

$$
i_{\text {corr }}=\mathrm{A} \exp \left(\frac{-E_{a}^{*}}{R T}\right)
$$

where $E_{\mathrm{a}}^{\mathrm{*}}$ is the apparent activation energy, $\mathrm{R}$ is the universal gas constant, $\mathrm{T}$ is the absolute temperature and $\mathrm{A}$ is the pre-exponential factor, the kinetic factor or the frequency factor.

Arrhenius plots of corrosion current densities are depicted in Fig. 9; they are represented by straight lines, indicating that the corrosion process was under activation control. 


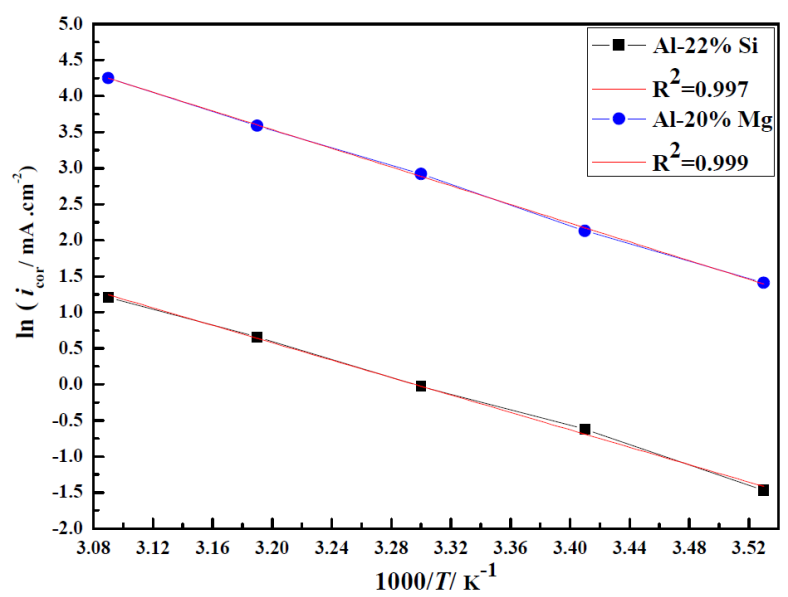

Figure 9. Arrhenius plots for the two $\mathrm{Al}$ alloys in $1 \mathrm{M} \mathrm{H}_{2} \mathrm{SO}_{4}$.

The thermo-kinetics parameters are listed in Table 3. The apparent activation energy values, corresponding to the two interfaces, are of the same order of magnitude, even if those of Al-22\% Si are slightly lower than those of Al-20\% $\mathrm{Mg}$. However the pre-exponential factor value of the latter is clearly the highest one. Generally, the corrosion rate increased with the decrease in the apparent activation energy, which represents the energetic barrier between the reactant and the transition state (activated complex). It is evident that it was not the case in the present study; this could be explained by the fact that the temperature exerted a more significant effect on the factor A values. It is known that a high A value is indicative of a higher frequency with which the energy barrier is crossed, resulting in the acceleration of the charge transfer process that governs the corrosion reaction [67]. This result is in accordance with those previously obtained by the electrochemical methods.

Table 3. Thermo-kinetics parameters of the two alloys in $1 \mathrm{M} \mathrm{H}_{2} \mathrm{SO}_{4}$.

\begin{tabular}{|l|c|c|c|}
\hline Alloys & $\left.\boldsymbol{E}_{a}^{*} / \mathbf{( k J . m o l}^{-\mathbf{1}}\right)$ & $\mathbf{A}$ & $\mathbf{R}^{\mathbf{2}}$ \\
\hline Al-22\%Si & 50.19 & $4.13 \times 10^{8}$ & 0.997 \\
Al- & 53.93 & $3.57 \times$ & 0.999 \\
\hline
\end{tabular}

\section{Conclusion}

A comparative investigation was performed on two industrial $\mathrm{Al}$ alloys in $1 \mathrm{M}$ $\mathrm{H}_{2} \mathrm{SO}_{4}$. The following conclusions can be drawn for their electrochemical degradability, in relation with their microstructure:

1-The obtained SEM micrographs and X-ray diffraction patterns reveal that Al$22 \% \mathrm{Si}$ microstructures are composed of primary silicon crystals, silicon-Al eutectic and $\alpha$ aluminum matrix, whereas, $\mathrm{Al}-20 \% \mathrm{Mg}$ alloy has a microstructure constituted by dendrites of $\alpha$ - aluminum and an eutectic matrix which is a combination of $\beta-\mathrm{Al}_{3} \mathrm{Mg}_{2}$ and $\alpha$ - aluminum .

2- The primary silicon phase of Al-22\% Si alloy formed the cathodic sites, whereas they are represented by the $\mathrm{Al}$ matrix in the case of the $\mathrm{Al}-20 \% \mathrm{Mg}$ alloy. The anodic reaction occurred on the Al matrix for the Al-Si alloy, but it 
took place on the intermetallic $\beta-\mathrm{Al}_{3} \mathrm{Mg}_{2}$ phase, in the case of the $\mathrm{Al}-\mathrm{Mg}$ alloy, leading to the dealloying of this alloy.

3- The results obtained by the EIS method were discussed using a suitable equivalent electrical circuit. One capacitive loop was obtained for $\mathrm{Al}-22 \% \mathrm{Si}$ and pure aluminum at $20{ }^{\circ} \mathrm{C}$; it could be assigned to the aluminum global oxidation in the two samples. However, three time constants describe the Al$20 \% \mathrm{Mg} / \mathrm{H}_{2} \mathrm{SO}_{4}$ interface; they can be attributed to the selective dissolution process of the intermetallic phase.

4- SEM micrographs are in good agreement with the electrochemical results, which reveal that the $\mathrm{Al}-20 \% \mathrm{Mg}$ alloy exhibited the lowest corrosion resistance in a $1 \mathrm{M} \mathrm{H}_{2} \mathrm{SO}_{4}$ solution.

\section{Acknowledgements}

This work was financially supported by "Ministère de l'enseignement supérieur et de la recherche scientifique (MESRS)", under the project No. E00220110061.

The authors are thankful to SNVI, "Société nationale des véhicules industriels", for kindly providing the materials used in this work.

\section{References}

1. Vargel C. Corrosion of Aluminum, Patent Attorney. Lyon: Elsevier; 2004.

2. Fridlyander IN, Sister VG, Grushko OE, et al. Aluminum Alloys: Promising Materials in the Automotive Industry. Met Sci Heat Treat. 2002;44:365.

3. Lakhtine I. Métallographie et traitements thermiques des métaux. $3^{\text {rd }}$ Ed. Moscow: Mir;1982. pp 367-386.

4. Moustafa MA, Samuel FH, Doty HW. Effect of solution heat treatment and additives on the microstructure of Al-Si (A413.1) automotive alloys. J Mater Sci. 2003;38:4507-4522.

5. Mohamed AMA, Samuel AM, Samuel FH, Doty HW. Influence of additives on the microstructure and tensile properties of near-eutectic Al-10.8\%Si cast alloy. Mater Des. 2009;30:3943-3957.

6. Tash M, Samuel FH, Mucciardi F, et al. Effect of metallurgical parameters on the machinability of heat-treated 356 and 319 aluminum alloys. Mater Sci Eng. 2006;443:207-217.

7. Sharma MM, Tomedi JD, Parks JM. A microscopic study on the corrosion fatigue of ultra-fine grained and conventional Al-Mg alloy. Corros Sci. 2015;93:180-190.

8. Jones RH, Baer DR, Danielson MJ, et al. Role of Mg in the stress corrosion cracking of an Al-Mg alloy. Metall Mater Trans A. 2001;32:1699-1711.

9. Wang Y, Liao H, Wu Y, et al. Effect of Si content on microstructure and mechanical properties of Al-Si-Mg alloys. Mater Des. 2014;53:634-638.

10. Mazhar AA, Arab ST, Noor EA. The role of chloride ions and $\mathrm{pH}$ in the corrosion and pitting of Al-Si alloys. J Appl Electrochem. 2001;31:11311140.

11. Scotto-Sheriff S, Darque-Ceretti E, Plassart G, et al. Physico-chemical characterisation of native air-formed oxide films on Al-Mg alloys at low temperature. Influence of water. J Mater Sci. 1999;34:5081-5088. 
12. Schmuki P. From Bacon to barriers: a review on the passivity of metals and alloys. J Solid State Electrochem. 2002;6:145-164.

13. Rehim SSA, Hassan HH, Amin MA. Corrosion and corrosion inhibition of Al and some alloys in sulphate solutions containing halide ions investigated by an impedance technique. Appl Surf Sci. 2002;187:279-290.

14. Li X, Deng S. Inhibition effect of Dendrocalamus brandisii leaves extract on aluminum in $\mathrm{HCl}, \mathrm{H}_{3} \mathrm{PO}_{4}$ solutions. Corros Sci. 2012;65:299-308.

15. Zhou B, Wang Y, Zuo Y. Evolution of the corrosion process of AA 2024-T3 in an alkaline $\mathrm{NaCl}$ solution with sodium dodecylbenzenesulfonate and lanthanum chloride inhibitors. Appl Surf Sci. 2015;357:735-744.

16. Ezuber H, El-Houd A, El-Shawesh F. A study on the corrosion behavior of aluminum alloys in seawater. Mater Des. 2008;29:801-805.

17. Moutarlier V, Gigandet MP, Pagetti J, et al. Molybdate/sulfuric acid anodising of 2024-aluminium alloy: influence of inhibitor concentration on film growth and on corrosion resistance. Surf Coat Technol. 2003;173:8795.

18. Soliman HN. Influence of 8-hydroxyquinoline addition on the corrosion behavior of commercial $\mathrm{Al}$ and $\mathrm{Al}-\mathrm{HO} 411$ alloys in $\mathrm{NaOH}$ aqueous media. Corros Sci. 2011;53:2994-3006.

19. Shahidi M, Gholamhosseinzadeh MR. Electrochemical evaluation of AA6061 aluminum alloy corrosion in citric acid solution without and with chloride ions. J Electroanal Chem 2015;757:8-17.

20. Rao AG, Katkar VA, Gunasekaran G, et al. Effect of multipass friction stir processing on corrosion resistance of hypereutectic Al-30Si alloy. Corros Sci. 2014;83:198-208.

21. Jing-hua J, Ai-bin MA, Dan S, et al. Corrosion behavior of hypereutectic Al$23 \% \mathrm{Si}$ alloy (AC9A) processed by severe plastic deformation. Trans Nonferrous Metals Soc China. 2010;80:195-200.

22. Shi WX, Gao B, Tu GF, et al. Effect of $\mathrm{Nd}$ on microstructure and wear resistance of hypereutectic Al-20\%Si alloy. J Alloys Compd. 2010;508:480485.

23. Fakhraei O, Emamy M, Farhangi H. The effect of Al-5Ti-1B grain refiner on the structure and tensile properties of Al-20\% Mg alloy. Mater Sci Eng A. 2013;560:148-153.

24. Hamana D, Nebti S, Hamamda S. Effect of the zirconium addition on the microstructure of Al +8 WT\% Mg alloy. Scr. Metall. Mater. 1990;24:20592064.

25. Jones RH, Baer DR, Danielson MJ, et al. Role of Mg in the stress corrosion cracking of an Al-Mg alloy. Metall. Mater. Trans. A. 2001;32:1699-1711.

26. Holtz RL, Pao PS, Bayles RA, et al. Corrosion-Fatigue Behavior of Aluminum Alloy 5083-H131 Sensitized at 448 K (175-C). Metall Mater Trans A. 2012;43:2839-2849.

27. Lyndon JA, Gupta RK, Gibson MA, et al. Electrochemical behaviour of the $\beta$-phase intermetallic $\left(\mathrm{Mg}_{2} \mathrm{Al}_{3}\right)$ as a function of $\mathrm{pH}$ as relevant to corrosion of aluminium, magnesium alloys. Corros Sci. 2013;70:290-293. 
28. Liu M, Schmutz P, Zanna S, et al. Electrochemical reactivity, surface composition and corrosion mechanisms of the complex metallic alloy $\mathrm{Al}_{3} \mathrm{Mg}_{2}$. Corros Sci. 2010;52:562-578.

29. Hackerman N, Snavely ES. Corrosion Basics.Houston: NACE; 1984. pp 127-146.

30. Stern M, Geary AL. Electrochemical Polarization I. A theoretical analysis of the shape of polarization curves. J Electrochem Soc. 1957;104:56-63.

31. Narayan Prabhu VVK. Review of Microstructure Evolution in Hypereutectic Al-Si Alloys and its Effect on Wear Properties. Trans Indian Inst Met. 2014;67:1-18.

32. Sediako DG, Kasprzak W. In Situ Study of Microstructure Evolution in Solidification of Hypereutectic Al-Si Alloys with Application of Thermal Analysis and Neutron Diffraction. Metall Mater Trans A. 2015;46:41604173.

33. Warmuzek M. Aluminum-silicon casting alloys: an atlas of microfractographs. ASM International; 2004.

34. $\mathrm{Xu} \mathrm{CL}$, Yang YF, Wang HY, et al. Effects of modification and heattreatment on the abrasive wear behavior of hypereutectic Al-Si alloys. J Mater Sci. 2007;42:6331-6338.

35. Murray JL. Alloy Phase Diagrams, H.Baker Edition. Ohio: ASM; 1992.

36. Fakhraei O, Emamy M. Effects of $\mathrm{Zr}$ and $\mathrm{B}$ on the structure and tensile properties of Al-20\%Mg alloy. Mater Des. 2014;56:557-564.

37. Boukerche I, Djerad S, Benmansour L, et al. Degradability of aluminum in acidic and alkaline solutions. Corros Sci. 2014;78:343-352.

38. Pourbaix M. Atlas d'equilibres electrochimiques. Paris: Gauthier-Villars; 1963.

39. Elkadi L, Mernari B, Traisnel M, et al. The inhibition action of 3,6-bis(2methoxyphenyl)-1,2-dihydro-1,2,4,5-tetrazine on the corrosion of mild steel in acidic media. Corros Sci. 2000;42:703-719.

40. Shahidi M, Gholamhosseinzadeh MR. Electrochemical evaluation of AA6061 aluminum alloy corrosion in citric acid solution without and with chloride ions. J Electroanal Chem. 2015;757:8-17.

41. Umoren SA, Li Y, Wang FH. Effect of aluminium microstructure on corrosion and inhibiting effect of polyacrylic acid in $\mathrm{H}_{2} \mathrm{SO}_{4}$ solution. $\mathrm{J}$ Appl Electrochem. 2011;41:307-315.

42. Umoren SA, Li Y, Wang FH. Effect of polyacrylic acid on the corrosion behaviour of aluminium in sulphuric acid solution. J Solid State Electrochem. 2010;14:2293-2305.

43. Holzer F, Müller S, Desilvestro J, et al. Aluminium alloys in sulphuric acid. Part I: Electrochemical behaviour of rotating and stationary disc electrodes. J Appl Electrochem. 1993;23:125-134.

44. Song GL, Atrens A. Corrosion Mechanisms of Magnesium Alloys. Adv Eng Mater. 1999;1:11-33.

45. Lim MCM, Scully JR, Kelly RG. Intergranular corrosion penetration in an Al-Mg Alloy as a function of electrochemical and metallurgical conditions. Corros Sci. 2013;69:35-47. 
46. Lopez DA, Simison SN, de Sanchez SR. Inhibitors performance in $\mathrm{CO}_{2}$ corrosion. Corros. Sci. 2005;47:735-755.

47. Moretti G, Guidi F, Grion G. Tryptamine as a green iron corrosion inhibitor in 0.5 M deaerated sulphuric acid. Corros Sci. 2004;46:387-403.

48. Conde A, de Damborenea J. Electrochemical modelling of exfoliation corrosion behaviour of 8090 alloy. Electrochim Acta. 1998;43:849-860.

49. Bessone J, Mayer C, Juttner K, et al. AC-impedance measurements on aluminium barrier type oxide films. Electrochim Acta. 1983;28:171-175.

50. Deng $\mathrm{S}$, Li X. Inhibition by Jasminum nudiflorum Lindl. leaves extract of the corrosion of aluminium in $\mathrm{HCl}$ solution. Corros Sci. 2012;64:253-262.

51. Brett CMA. On the electrochemical behaviour of aluminium in acidic chloride solution. Corros Sci. 1992;33:203-210.

52. de Wit JHW, Lenderink HJW. Electrochemical impedance spectroscopy as a tool to obtain mechanistic information on the passive behaviour of aluminium. Electrochim Acta. 1996;41:1111-1119.

53. Saviour A, Umoren YL, Wang FH. Effect of polyacrylic acid on the corrosion behaviour of aluminium in sulphuric acid solution. J Solid State Electrochem. 2010;14:2293-2305.

54. Song G. Recent Progress in Corrosion and Protection of Magnesium Alloys. Adv Eng Mater. 2005;7:563-586.

55. Song G, Atrens A, John DS, et al. The anodic dissolution of magnesium in chloride and sulphate solutions. Corros Sci. 1997;39:1981-2004.

56. Li X, Deng S, Fu H. Sodium molybdate as a corrosion inhibitor for aluminium in $\mathrm{H}_{3} \mathrm{PO}_{4}$ solution. Corros Sci. 2011;53:2748-2753.

57. Frers SE, Stefenel MM, Mayer C, et al. AC-Impedance measurements on aluminium in chloride containing solutions and below the pitting potential. $\mathrm{J}$ Appl Electrochem. 1990;20:996-999.

58. Valand T, Heusler KE. Reactions at the oxide-electrolyte interface of anodic oxide films on aluminum. J Electroanal Chem. Interfacial Electrochem. 1983;149:71-82.

59. Macdonald JR. Impedance spectroscopy and its use in analyzing the steadystate AC response of solid and liquid electrolytes. J Electroanal Chem Interfacial Electrochem. 1987;223:25-50.

60. Souto RM, Fernandez-Marida L, Gonzalez S, et al. Comparative EIS study of different $\mathrm{Zn}$-based intermediate metallic layers in coil-coated steels. Corros Sci. 2006;48:1182-1192.

61. Wang B, Du M, Zhang J, et al. Electrochemical and surface analysis studies on corrosion inhibition of Q235 steel by imidazoline derivative against $\mathrm{CO}_{2}$ corrosion. Corros Sci. 2011;53:353-361.

62. Gudić S, Smoljko I, Kliškić M. The effect of small addition of tin and indium on the corrosion behavior of aluminium in chloride solution. J Alloys Compd. 2010;505:54-63.

63. Brug GJ, van den Eeden ALG, Sluyters-Rehbach M, et al. The analysis of electrode impedances complicated by the presence of a constant phase element. J Electroanal Chem Interfacial Electrochem. 1984;176:275-295. 
64. Qing Q, Lei L, Shuan J, et al. Effect of sodium molybdate on the corrosion behavior of cold rolled steel in peracetic acid solution. J Appl Electrochem. 2009;39:569-576.

65. Bonnel A, Dabosi F, Deslouis C, et al. Corrosion Study of a Carbon Steel in Neutral Chloride Solutions by Impedance Techniques. J Electrochem Soc. 1983; 130:753.

66. Landolt D. Corrosion et chimie de surfaces des métaux. Lausanne: Presses polytechniques et universitaires romandes; 1993.

67. Bard AJ, Faulkner LR, York N, et al. Electrochemical methods. Fundamentals and applications. New York: Wiley;1944.

68. Pavlov D, Bojinov M, Laitinen T, et al. Electrochemical behaviour of the antimony electrode in sulphuric acid solutions-I. Corrosion processes and anodic dissolution of antimony. Electrochim Acta. 1991;36:2081-2086. 